\title{
Eerste evaluatie bij slangenbeet door huisarts?
}

Het Nationaal Vergiftigingen Informatie Centrum (NVIC) onderschrijft niet de bewering van Vendrik en co-auteurs dat de huisarts bij slangenbeten uitstekend in staat is een eerste evaluatie uit te voeren - algemene beoordeling van de patiënt, immobilisatie van de aangedane extremiteit, achterhalen van de soort en giftigheid. ${ }^{1}$ Deze bewering is zelfs gevaarlijk. De ontwikkeling van het klinisch beeld na een beet door een exotische gifslang kan snel verlopen. Bij het NVIC zijn beetincidenten in Nederland bekend waarbij patiënten binnen één tot anderhalf uur na de beet en langer dan twintig minuten na het optreden van de eerste neurotoxische verschijnselen geïntubeerd en beademd moesten worden. Eén patiëntbespreking hierover wordt zelfs aangehaald door de auteurs. ${ }^{2}$ Immobilisatie van de aangedane extremiteit kan dit niet voorkomen!

\section{OBERVATIE IN ZIEKENHUIS}

In geval van een beet door een onbekende, exotische slangensoort moet de patiënt geobserveerd worden in een ziekenhuis, totdat bewezen is dat het een niet giftige soort betreft. Hierbij is het wenselijk de aanbevelingen voor (frequentie van) lichamelijk onderzoek en laboratoriumbepalingen conform het protocol Exotische (gif)slangenbeet te volgen. ${ }^{3}$ Observatie van de patiënt op meerdere locaties leidt tot tijdsverlies en meer transportbewegingen, wat de immobilisatie niet ten goede komt. Ook patiënten gebeten door de Nederlandse adder dienen bij voorkeur in het ziekenhuis geobserveerd te worden, zeker als het om kinderen gaat.

Ten slotte: identificatie van een onbekende slang moet een professional doen. Figuur 3 met kenmerken van giftige en niet-giftige slangen is een ernstige vereenvoudiging van de werkelijkheid. Er zijn vele uitzonderingen en dit schema is geen betrouwbare leidraad. Zo is bijvoorbeeld triage op basis van beetkenmerken niet mogelijk; hebben krasvormige beetkenmerken geleid tot fatale intoxicaties, en bestaat er geen relatie tussen de kleur en de giftigheid van een slang.

\section{Marieke Dijkman}

\section{LITERATUUR}

1. Vendrik J, Stijnis K, Ridderrikhof M, Van Thiel P. Slangenbeten in Nederland. Huisarts Wet 2018;61(7):47-9. DOI: 10.1007/s12445018-0196-y.

2. Dijkman MA, De Vries I, Van Dam M, De Lange DW. Gebeten door een exotische gifslang. Ned Tijdschr Geneeskd 2017;161:D822.

3. www.vergiftigingen.info, zie lijst van behandelingen.

\section{REACTIE}

De auteurs danken de medewerkers van het NVIC voor hun commentaar. Patiënten met een slangenbeet melden zich soms bij de huisarts en niet-rechtstreeks op de spoedeisende hulp. Wij onderschrijven de noodzaak om snel en laagdrempelig te overleggen na een slangenbeet. We wilden slechts een handvat voor een eerste inschatting bieden aan de huisarts die met een slangenbeet wordt geconfronteerd. Als wij de indruk hebben gewekt dat de huisarts een dergelijke casus zonder enige spoed zelfstandig af zou kunnen handelen, betreuren wij dat.

Ook onderschrijven wij de noodzaak tot nauwkeurige differentiatie van de betreffende slang, waarbij de huisarts belangrijke informatie kan verschaffen over uiterlijke kenmerken van de slang. De gevoegde figuur is slechts ter illustratie bedoeld, een uitgebreide determinatie van deze dieren behoort niet tot ons vakgebied of dat van de huisarts. Contact met een gespecialiseerd centrum zoals het NVIC is sterk aan te bevelen.

Jeroen Vendrik

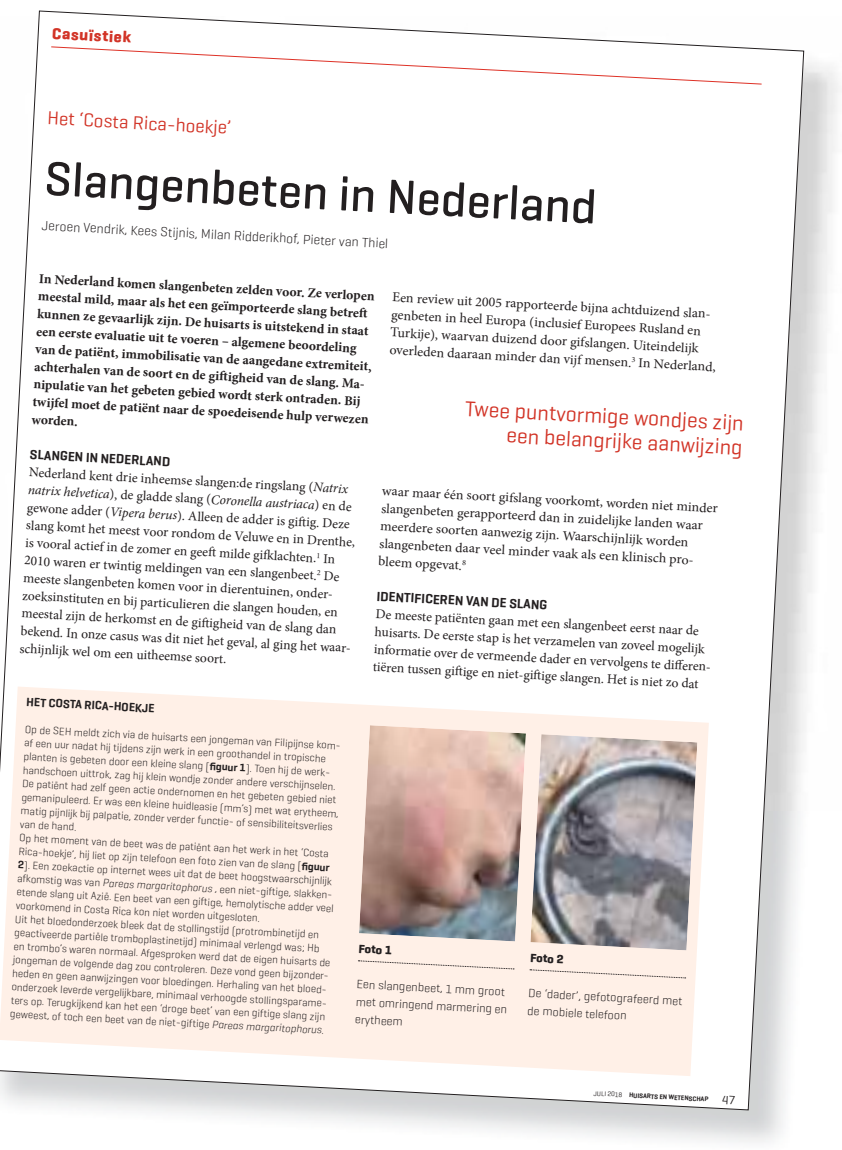

